\title{
Controlling Foam Morphology of Poly(methyl methacrylate) via Surface Chemistry and Concentration of Silica Nanoparticles and Supercritical Carbon Dioxide Process Parameters
}

\author{
Deniz Rende, Linda S. Schadler, and Rahmi Ozisik \\ Department of Materials Science and Engineering and Rensselaer Nanotechnology Center, Rensselaer Polytechnic Institute, \\ Troy, NY 12180, USA \\ Correspondence should be addressed to Rahmi Ozisik; ozisik@rpi.edu
}

Received 16 February 2013; Accepted 29 April 2013

Academic Editor: Ignacio Gracia Fernández

Copyright (C) 2013 Deniz Rende et al. This is an open access article distributed under the Creative Commons Attribution License, which permits unrestricted use, distribution, and reproduction in any medium, provided the original work is properly cited.

\begin{abstract}
Polymer nanocomposite foams have received considerable attention because of their potential use in advanced applications such as bone scaffolds, food packaging, and transportation materials due to their low density and enhanced mechanical, thermal, and electrical properties compared to traditional polymer foams. In this study, silica nanofillers were used as nucleating agents and supercritical carbon dioxide as the foaming agent. The use of nanofillers provides an interface upon which $\mathrm{CO}_{2}$ nucleates and leads to remarkably low average cell sizes while improving cell density (number of cells per unit volume). In this study, the effect of concentration, the extent of surface modification of silica nanofillers with $\mathrm{CO}_{2}$-philic chemical groups, and supercritical carbon dioxide process conditions on the foam morphology of poly(methyl methacrylate), PMMA, were systematically investigated to shed light on the relative importance of material and process parameters. The silica nanoparticles were chemically modified with tridecafluoro-1,1,2,2-tetrahydrooctyl triethoxysilane leading to three different surface chemistries. The silica concentration was varied from 0.85 to $3.2 \%$ (by weight). The supercritical $\mathrm{CO}_{2}$ foaming was performed at four different temperatures $(40,65,75$, and $85^{\circ} \mathrm{C}$ ) and between 8.97 and $17.93 \mathrm{MPa}$. By altering the surface chemistry of the silica nanofiller and manipulating the process conditions, the average cell diameter was decreased from $9.62 \pm 5.22$ to $1.06 \pm 0.32 \mu \mathrm{m}$, whereas, the cell density was increased from $7.5 \pm 0.5 \times 10^{8}$ to $4.8 \pm 0.3 \times 10^{11}$ cells $/ \mathrm{cm}^{3}$. Our findings indicate that surface modification of silica nanoparticles with $\mathrm{CO}_{2}-\mathrm{philic}$ surfactants has the strongest effect on foam morphology.
\end{abstract}

\section{Introduction}

In nature, foams are found in the form of bone, natural sponge, coral, and natural cork. Inspired by these materials, processing of polymer foams has received considerable attention $[1,2]$. Polymer nanocomposite foams are micro- and nanoporous materials that are used as thermal and sound barriers, shock absorbers, absorbents, cushions, and tissue engineering scaffolds $[3,4]$. Recent advances in processing of polymer nanocomposite foams enabled new application areas in hydrogen storage [5], electromagnetic shielding [6], and sensing technology [7]. Various polymers are being used in foam applications such as polyurethane, polystyrene, polyethylene, polypropylene, poly(vinyl chloride), polycarbonate, and poly(methyl methacrylate) [8-14] as well as specialty polymers.
Foams are divided into various categories depending on their pore morphology (open versus closed) or density (low versus high). Open cell morphology consists of pores (bubbles) that are connected to each other, making the material softer and more absorbent. In the closed cell morphology, the pores are isolated from each other, which makes the foam more rigid. In addition to these categories, polymer foams can also be characterized according to their density, cell size, cell density, and wall thickness, all of which influence the properties of the foam. In general, polymer foams have low thermal conductivity, poor mechanical properties, and poor surface quality due to the underlying porous structure. However, their low density, low thermal conductivity, and sound barrier properties make them highly attractive for a variety of applications. For example, low density foams are primarily used in packaging and insulation applications, 
and high density foams are used in structural applications $[3,15]$ as thermal or sound barriers. Polymer foams can also be categorized by their flexibility: flexible, semiflexible, and rigid. Flexible and semiflexible polymer foams are used to produce cushions, textiles, toy parts, and sporting goods. On the other hand, rigid polymer foams have applications in insulation, construction, durable goods, and infrastructure.

In general, the foam morphology is formed via the use of foaming agents, which undergo phase transition either due to physical or chemical changes creating a gas phase that expands forming gas bubbles inside the polymer matrix. The nucleation of the bubbles occurs via two different classical mechanisms: homogeneous or heterogeneous nucleation. In the homogeneous nucleation case, concurrent initiation and growth of bubbles are observed leading to a wide cell size distribution in the final foam structure. The heterogeneous nucleation, however, requires the existence of a secondary material that promotes simultaneous growth of bubbles inside the polymer matrix, resulting in a narrow cell size distribution. The addition of inorganic nanoparticles, which act as nucleating agents, induces heterogeneous nucleation and provides a large number of nucleation sites. Furthermore, the presence of micro- or nanosized fillers dramatically decreases the energy barrier for cell nucleation compared to that required for homogeneous nucleation $[9,13,16$, 17]. Existing models based on classical nucleation theories sometimes fail to explain the nucleation satisfactorily. Other models, for example, consider microvoids as nucleation sites. Microvoids lead to stress induced bubble formation, and the population of sufficiently large viable microvoids that overcomes surface and elastic forces can then be related to the cell density [18-20].

The synthesis of nanofillers is of recent interest because they provide a high density of nucleation sites at low concentrations. The highest nucleation efficiency is achieved when nucleation on the filler surface is energetically favorable and the filler is uniformly distributed and dispersed within the polymer matrix. Therefore, heterogeneous nucleation conditions could be controlled to some extent via filler type, geometry (size, aspect ratio, etc.), and surface chemistry $[1,21,22]$. Selection of the filler type is an important step to achieve the final desired properties. For instance, carbon based nanofillers (carbon nanotubes and graphene) enhance the strength and conductivity $[8,23]$. The flat surfaces of clays offer an excellent surface for nucleation; however only when dispersion is controlled, uniform cell size and remarkable mechanical properties are achieved [24-29]. Spherical nanofillers are another class of fillers that are being used to create polymeric foams [21,30], polymer blends [31], and copolymers [32]. Among spherical nanoparticles, silica nanoparticles have been widely used as bare or after surface modification with vinyl or fluorinated silane coupling agents to foam polymers. Studies using bare silica nanoparticles showed a reduction in the average cell size with increasing concentration [33]. The surface modification of silica nanoparticles was reported to lead to enhanced interaction between the foaming agent and the nanofiller, thereby reducing the average cell size further [34]. For example, Goren et al. reported an 8-fold decrease in average cell size after modifying silica nanoparticles with fluorinated silane coupling agents [21]. However, spherical nanoparticles do not improve properties as much as nanosized rods or sheets.

In addition to filler characteristics, foaming conditions also influence the final foam structure. Conventional foamed products can be produced either by chemical or physical blowing agents. Chemical blowing agents are mixed into polymer matrix and decompose when heated up yielding a gas release. This process requires an additional step to eliminate the residual chemical blowing agent [35]. Due to the challenges in the removal of side products, physical foaming is often preferred over chemical foaming. Physical foaming involves the saturation of the polymer matrix with a gas at high pressure followed by a rapid decrease in pressure. This rapid decrease in pressure leads to the expansion of the gas and, therefore, results in the formation of bubbles within the polymer matrix. The lack of hazardous chemical solvent use during physical foaming makes this technique the preferred method in the production of polymeric foams. Supercritical fluids have also become an attractive option for the production of polymer foams. Due to stable, nontoxic, inflammable, low cost and its easily attainable critical conditions, supercritical carbon dioxide has been widely used to create polymer foams [14, 21-23, 29]. Supercritical $\mathrm{CO}_{2}$ exhibits relatively high solubility in polymers, acts as a plasticizer by lowering the glass transition temperature, easily diffuses into the polymer, reduces the viscosity and surface tension of the polymer melt, and assists in polymer processing. Foaming with supercritical $\mathrm{CO}_{2}$ can be performed either as a batch process, where the samples are kept in a pressure chamber and saturated with supercritical carbon dioxide $[14,21,36]$, or as a continuous process such as the inside of an extruder [3739]. After the polymer is saturated with supercritical $\mathrm{CO}_{2}$, the rapid decrease in pressure generates a thermodynamic instability, which leads to phase transition from supercritical to gaseous state and causes the nucleation of gas bubbles. Saturation $\left(\mathrm{CO}_{2}\right.$ soaking) pressure, temperature, time, and depressurization rate are critical parameters in determining the final morphology of the polymer foam [40]. At high pressures, more carbon dioxide is absorbed into the polymer, leading to an increase in cell density [41]. In addition, high pressure enhances the driving force for cell growth.

Many researchers investigated the silica/PMMA nanocomposite systems foamed with supercritical $\mathrm{CO}_{2}$ and a review article by Chen and coworkers [42] discusses many of the recent developments. Siripurapu et al. [33] studied the effect of concentration of untreated (bare) silica nanoparticles at 1,5 , and $8 \%$ silica concentrations. The foamed material was produced with $\mathrm{CO}_{2}$ at $40^{\circ} \mathrm{C}$ and 6.83 MPa. An increase in nanosilica concentration led to reduced average cell diameter and increased cell density under isothermal and isobaric conditions. Yeh et al. [34] highlighted the importance of surface modification of silica nanoparticles, which might influence the interaction of filler with $\mathrm{CO}_{2}$. For example, at various concentrations untreated and vinyl-modified silica nanoparticles containing PMMA composites were foamed at $150^{\circ} \mathrm{C}$ and $13.8 \mathrm{MPa}$. The cell sizes achieved in this process ranged from 10 to $23 \mu \mathrm{m}$. The surface 
modification of silica nanoparticles was also performed with fluorinated silane coupling agents by our group [21], in which the silica nanoparticle sizes ranged from 60 to $150 \mathrm{~nm}$. PMMA nanocomposites having $1 \%$ silica with 66 , 80,149 , and $157 \mathrm{~nm}$ silica nanoparticles were foamed under supercritical $\mathrm{CO}_{2}$ at $40^{\circ} \mathrm{C}$ and $17.93 \mathrm{MPa}$. In this study, the particle size was shown to have an important contribution to cell density and fluorination of the silica nanoparticles was shown to facilitate the dispersion of the silica nanoparticles inside the PMMA matrix.

Although nanofiller concentration and surface chemistry are known to have strong influence on the final cell size and cell density $[14,21,43,44]$, the extent of surface coverage (tethering density) of the functional groups on the foam morphology is yet to be reported in a systematic manner. In the current study, we aim to investigate the effect of tethering density of fluoroalkanes on the foam morphology of silica/PMMA nanocomposites. Fluorinated surface modifiers were chosen because they were shown to exhibit $\mathrm{CO}_{2}$-philic behavior [21]. The effects of silica concentration, foaming temperature, and saturation pressure on the final foam morphology were also investigated.

\section{Experimental}

2.1. Materials. To synthesize silica nanoparticles, tetraethyl orthosilicate (TEOS, 98\% reagent grade, Sigma, 131903) and ammonia solution $\left(\mathrm{NH}_{3}, 28 \%\right.$, Sigma, 338818) were used as received. Tetrahydrofuran (THF, Fisher Scientific, T397-1) was used to purify the silica nanoparticles. The surface modification of the silica nanoparticles was performed with silane coupling agent tridecafluoro-1,1,2,2tetrahydrooctyl triethoxysilane (F-TEOS, Gelest, SIT8175). Poly(methyl methacrylate), PMMA, was chosen as the matrix polymer because of its outstanding chemicophysical properties [45] and relatively high affinity for $\mathrm{CO}_{2}$. Commercial grade PMMA (Plexiglas V920-100) was donated by Altuglas International.

2.2. Preparation of Silica Nanoparticles. The method used in the synthesis of silica nanoparticles is an adaptation of the Stöber's procedure [46]. To prepare $100 \mathrm{~nm}$ bare silica nanoparticles, $87.5 \mathrm{~g}$ ethanol, $4.37 \mathrm{~g}$ distilled water, and $4.12 \mathrm{~g}$ ammonia solution was mixed with $8.62 \mathrm{~g}$ of TEOS. The reaction mixture was stirred overnight at room temperature and unreacted solvents were removed by rotary evaporator at $60^{\circ} \mathrm{C}$ and $90 \mathrm{rpm}$ for 2 hours. The sample was then kept in vacuum dryer overnight at $60^{\circ} \mathrm{C}$. In order to remove any organic and inorganic impurities and unused reactants, the dried sample was first washed with THF and vacuum-filtered through $0.45 \mu \mathrm{m}$ hydrophobic filtering paper, then washed with distilled water, and vacuum-filtered through $0.45 \mu \mathrm{m}$ hydrophilic filtering paper. Finally, the sample was dried again in vacuum oven overnight at $60^{\circ} \mathrm{C}$. This procedure approximately yields $1.5 \mathrm{~g}$ of bare silica nanoparticles with an average size of $\sim 100 \mathrm{~nm}$.

2.3. Surface Modification of Silica Nanoparticles. In order to increase the interaction of silica and $\mathrm{CO}_{2}$, silica nanoparticles were modified by tethering fluoroalkane chains (F-TEOS) onto their surfaces. To prepare the surface modified nanoparticles, silica nanoparticles were synthesized as described before and each batch was divided into multiple parts; one was left as is (bare silica) and the other parts were modified with F-TEOS. This ensured that the starting silica nanoparticles on average had the same size. Two different amounts ( 0.1 and $0.7 \mathrm{~g}$ ) of F-TEOS were added to two different silica batches to create two different surface tethering densities. The surface modification reaction took $24 \mathrm{hr}$ at room temperature. Unreacted solvent was removed by rotary evaporator at $60^{\circ} \mathrm{C}$ and $90 \mathrm{rpm}$ for 2 hours, and the samples were dried in a vacuum oven overnight at $60^{\circ} \mathrm{C}$. To remove any residual solvent and impurities, each sample was subsequently washed with THF and water, filtered, and dried in vacuum oven overnight at $60^{\circ} \mathrm{C}$.

2.4. Structural Analysis of Silica Nanoparticles. The size of the bare and surface modified nanoparticles was characterized by field emission scanning electron microscopy (SEM), transmission electron microscopy (TEM), and image processing. After the synthesis, the bare and surface modified silica nanoparticles were dried and the nanoparticles were first subjected to gold sputtering to form a $10-15 \mathrm{~nm}$ layer of gold on the sample surface. SEM images were obtained with a JEOL JSM-6332 using an accelerating voltage of $10 \mathrm{kV}$. TEM images were collected with a Philips CM12 with an accelerating voltage of $120 \mathrm{kV}$. Subsequently, both SEM and TEM images were analyzed with ImageJ [47] and diameter measurements of at least 100 nanoparticles were recorded in order to have statistically significant results.

The extent of the surface modification was determined by thermogravimetric analysis (TGA). Each silica nanoparticle sample was analyzed by TA Instruments TGA Q50 by heating up to $900^{\circ} \mathrm{C}$ at a rate of $20^{\circ} \mathrm{C} / \mathrm{min}$. The resulting percent weight changes between 200 and $800^{\circ} \mathrm{C}$ were used to calculate the percent coverage of the silica surface. Both bare and surface fluorinated samples were tested for at least three times.

The surface area of the silica nanoparticles was measured with Quantachrome BET Surface Analyzer Autosorb. Before BET analysis, the samples were degassed at $150^{\circ} \mathrm{C}$ under nitrogen atmosphere for $24 \mathrm{hrs}$.

2.5. Preparation of Polymer Nanocomposites. The polymer nanocomposite samples were prepared by melt mixing with a benchtop twin-screw extruder (Haake MiniLab). The extruder was equilibrated for $2 \mathrm{hrs}$ at $220^{\circ} \mathrm{C}$ before each use. The rotation speed of the screws was set to $60 \mathrm{rpm}$. Before each operation, $5 \mathrm{~g}$ of neat PMMA was passed through the system to clean the screws. The samples with different concentrations of bare and surface modified silica nanoparticles were mixed with PMMA and each sample was cycled within the extruder for $4 \mathrm{~min}$ and flushed in $3 \mathrm{~min}$. These parameters were chosen because they were previously shown to disperse and distribute silica nanoparticles effectively [21]. Neat PMMA samples were also processed in the same way as silica containing PMMA as control samples. 
Although silica was added to PMMA in premeasured amounts, due to the chaotic nature of the twin-screw extruder used, silica concentration in silica/PMMA composites was subsequently measured again by thermogravimetric analysis (TA Instruments). For statistical accuracy, three different samples, each being approximately $40 \mathrm{mg}$, were analyzed with a TA Instruments TGA Q50 by heating to $900^{\circ} \mathrm{C}$ at a rate of $20^{\circ} \mathrm{C} / \mathrm{min}$. The silica concentration was determined from the remaining weight at $800^{\circ} \mathrm{C}$, after which the weight remains constant. The melt mixing process led to several composite samples each having slightly different amount of bare or surface modified silica nanoparticles. In order to establish statistical significance, these samples were separated into two groups of "low" and "high" silica concentrations. The low silica concentration group contained $0.85-1.38 \%$ silica and the high concentration group contained $2.5-3.2 \%$ silica. All silica concentrations are reported as weight percentages. Another $2.9 \%$ silica/PMMA nanocomposite sample was prepared with highly surface modified silica nanoparticles. This sample was used specifically to investigate the effect of supercritical $\mathrm{CO}_{2}$ process parameters on foam morphology while eliminating sample variations and effect of surface modification. The nanocomposite samples were labeled according to their silica surface tethering density (B: bare; F: fluorinated with low tethering density; and FF: fluorinated with high tethering density) and silica concentration (low or high). For instance, B-Low indicates a nanocomposite sample containing bare silica nanoparticles at low concentration $(0.85 \%)$. The neat PMMA control sample was labeled as "PMMA." This labeling convention was necessitated by the fact that during sample preparation neither the surface tethering density nor the silica concentration could be controlled accurately.

2.6. Foaming with Supercritical Carbon Dioxide. A batch foaming process was performed to prepare polymer nanocomposite foams using supercritical $\mathrm{CO}_{2}$ as the foaming agent. A high-pressure reactor (Parr, 5512, $50 \mathrm{~mL}$ ) was connected to a Teledyne ISCO high-pressure syringe pump. The polymer nanocomposite extrudes were cut into $1-2 \mathrm{~cm}$ long pieces and were placed in the pressure chamber. The samples were then saturated with supercritical $\mathrm{CO}_{2}$ and were kept at predetermined temperature and pressure for $24 \mathrm{hrs}$ (the exact processing conditions are provided in Section 3). After saturation with supercritical $\mathrm{CO}_{2}$ for 24 hours, the pressure was decreased at a rate of $1.5 \mathrm{MPa} / \mathrm{s}$. The samples were removed from the pressure chamber and were soaked in water that was maintained at $60-65^{\circ} \mathrm{C}$ for one minute.

2.7. Determination of Foam Morphology and Cell Size Distribution. The foam morphology was investigated using field emission scanning electron microscope (SEM, JEOL JSM6332). Samples were freeze-fractured in liquid nitrogen and the fracture surfaces were sputter-coated with $10-15 \mathrm{~nm}$ of gold. The images were then collected under $15 \mathrm{kV}$ accelerating voltage. SEM images of the fracture surfaces, both from the center and near the perimeter, were recorded with SEM for image processing with ImageJ [47].

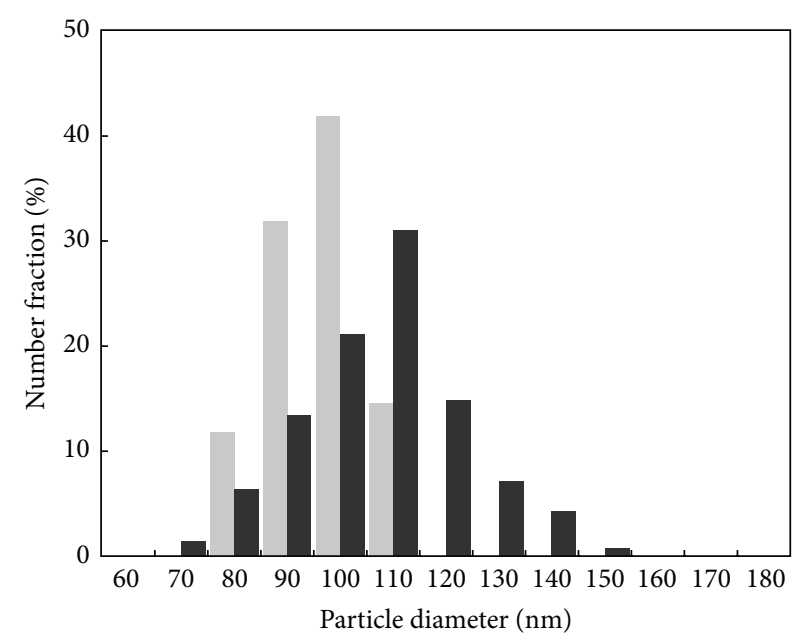

$\begin{array}{ll}\text { (a) } & \text { Bare } \\ & N=110 \\ & D_{\text {avg }}=101.2 \pm 0.8 \mathrm{~nm} \\ & \\ \text { (b) } \square & \text { Surface modified } \\ & N=130 \\ & D_{\text {avg }}=112.4 \pm 1.3 \mathrm{~nm}\end{array}$

FIGURE 1: Size distribution of (a) bare and (b) surface modified silica nanoparticles. Surface modified silica samples include both F and FF samples.

\section{Results and Discussion}

3.1. Nanoparticle Size. The size of the silica nanoparticles was determined by image analysis of transmission electron micrographs (TEM). Figure 1 shows the size distribution of bare and surface modified silica nanoparticles. Since the surface modified nanoparticles were prepared from the same batch as the bare silica nanoparticles, only one size distribution graph is presented. The average diameters were found to be $101.2 \pm 0.8 \mathrm{~nm}$ for bare silica nanoparticles and $112.4 \pm 1.3 \mathrm{~nm}$ for modified silica nanoparticles.

3.2. Tethering Density. As explained in Section 2, in order to ensure that the surface modified nanoparticles had the same starting size as bare silica nanoparticles, after the synthesis of the nanoparticles, the batch was divided into two groups and 0.1 and $0.7 \mathrm{~g}$ F-TEOS were added to prepare low $(\mathrm{F})$ and high (FF) fluorinated surfaces. According to the molecular structure of the surface modifier, F-TEOS (Figure 2(a)), the reaction yields ethanol (Figure 2(b)). Fluorinated alkylsilane derivatives react with the surface hydroxyl groups on silica surface and form self-assembled monolayers or multilayers [48]. The triethoxysilane group can be attached to the surface in three different configurations (Figure 2(b)). If the silane coupling agent is attached to the surface via one or two silane groups (as shown by mechanisms I and II in Figure 2(b)), the remaining silane group(s) may react with neighboring tethered or free F-TEOS molecules resulting in multiple layers on the surface. 


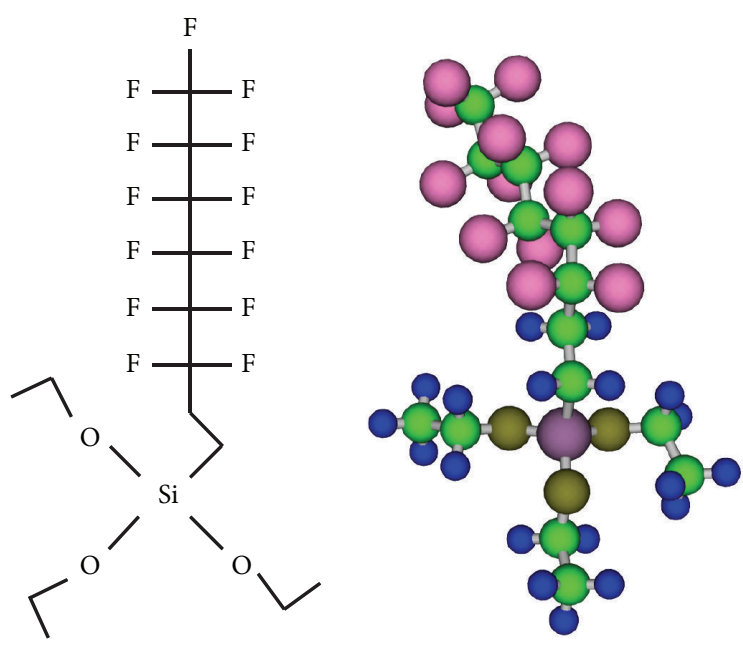

(a)

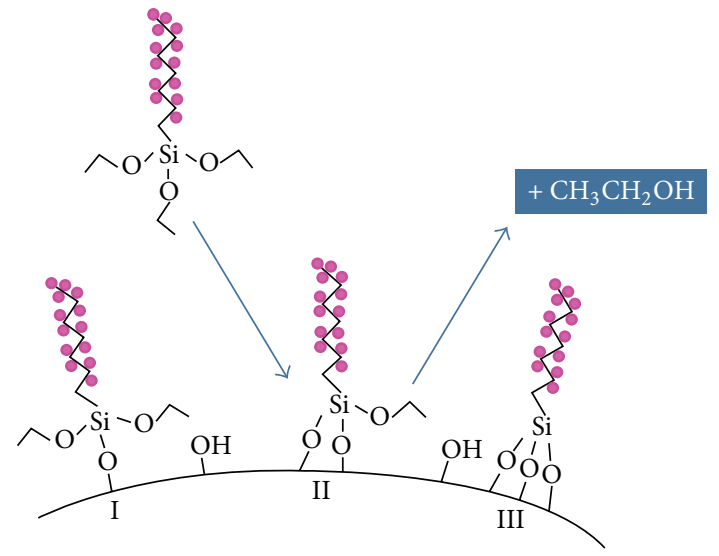

(b)

Figure 2: (a) The structure of F-TEOS. (b) Possible reaction mechanisms of the surface modifier, F-TEOS, with hydroxyl groups on silica. Three possible attachments of F-TEOS to the silica surface are possible. Mechanisms I and II leave ethoxysilane groups on F-TEOS that might react with neighboring tethered or free F-TEOS groups resulting in multilayered coverage on the silica nanoparticle.

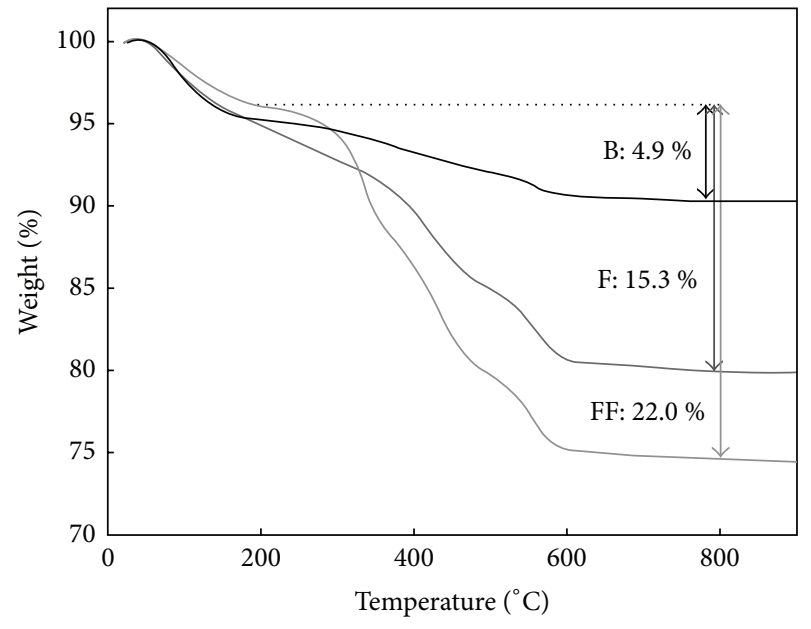

FIGURE 3: Thermogravimetric analysis of bare and fluorinated silica nanoparticles. B denotes the untreated silica nanoparticles. $\mathrm{F}$ and FF denote the low and high fluorinated samples, respectively. The weight loss between 200 and $800^{\circ} \mathrm{C}$ for each sample is presented next to the sample label.

A quantitative analysis of the F-TEOS coverage on the silica nanoparticle surfaces was performed by thermogravimetric analysis (Figure 3). Using untreated silica nanoparticle weight change $\left(\Delta w_{\mathrm{B}_{-} \mathrm{SiO}_{2}}\right)$ between 200 and $800^{\circ} \mathrm{C}$ as the reference, the following calculation provided the percent surface coverage of the silica nanoparticles [49]:

$$
n_{\text {silane }}=\frac{\Delta w_{\mathrm{F}_{-} \mathrm{SiO}_{2}}-\Delta w_{\mathrm{B}-\mathrm{SiO}_{2}}}{100 \cdot M_{\text {mod }} \cdot \sigma},
$$

where $n_{\text {silane }}$ is the number of moles of silane, $\Delta w_{\mathrm{F}-\mathrm{SiO}_{2}}$ is the percent weight change of fluorinated silica nanoparticles
TABLE 1: Surface coverage of silica nanoparticles according to different reaction mechanisms as calculated from (1).

\begin{tabular}{lccc}
\hline Mechanism & I & II & III \\
\hline F & $68.2 \%$ & $72.6 \%$ & $77.6 \%$ \\
FF & $112.2 \%$ & $119.4 \%$ & $127.5 \%$ \\
\hline
\end{tabular}

(between 200 and $800^{\circ} \mathrm{C}$ ), $M_{\text {mod }}$ is the molecular mass that is lost (as volatile gas) between 200 and $800^{\circ} \mathrm{C}$ per mole of used silane, and $\sigma$ is the specific surface area of the silica nanoparticles and was measured with BET surface analysis, which yielded specific surface areas of $32.6 \mathrm{~m}^{2} / \mathrm{g}$ for bare nanoparticles and $33.9 \mathrm{~m}^{2} / \mathrm{g}$ for the surface modified nanoparticles. For reaction mechanisms shown in Figure 2(b), the molecular weights of the remaining silane group on the silica $\left(M_{\bmod }\right)$ were $481.36,452.36$, and $423.36 \mathrm{~g} / \mathrm{mol}$ corresponding to single, double, and triple ethoxysilane attachments. In order to assess surface coverage, $n_{\text {silane }}$ obtained from (1) needs to be compared to $n_{\text {hydroxyl }}$. According to Zhuravlev [50], silica nanoparticles with an average size of $100 \mathrm{~nm}$ contain 5.85 hydroxyl groups per square nanometer; therefore, if (1) yields over 5.85 silane groups (on $100 \mathrm{~nm}$ sized silica), the surface coverage would be over $100 \%$, which can be explained only by the presence of a multilayer silane coverage as suggested by reaction mechanisms I and II in Figure 2(b).

Table 1 presents surface coverages calculated via (1) for each possible reaction mechanism presented in Figure 2(b). This calculation showed that low fluorinated silica nanoparticles (F) have a surface coverage around $73 \%$, whereas this value exceeds $100 \%$ for the highly fluorinated silica nanoparticles (FF) indicating multilayer formation.

The silica nanoparticles prepared in the current study can be summarized as follows. (i) The average size of silica 


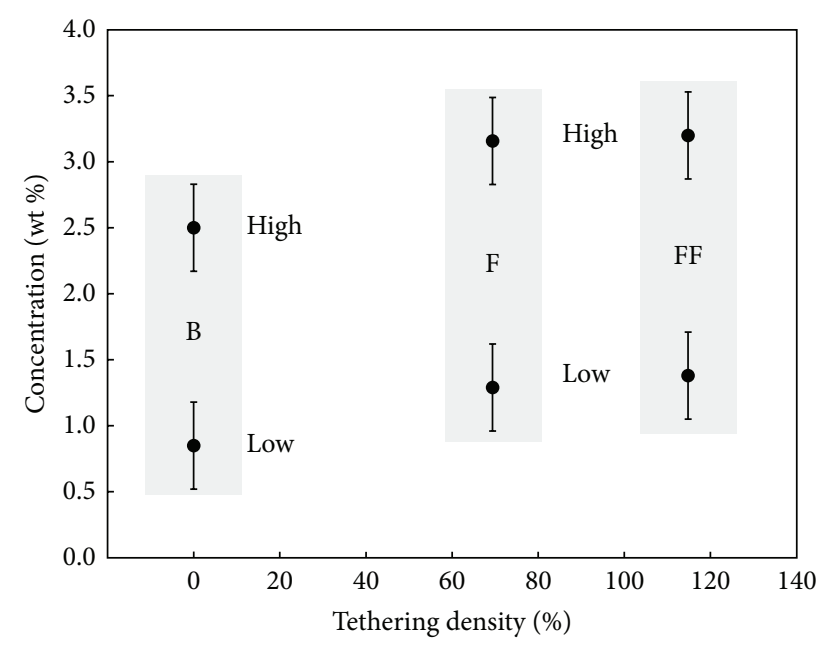

- Neat PMMA

FIgURE 4: The concentration of the B (bare), F ( 73\% surface coverage) and FF (>100\% surface coverage) silica nanoparticles in PMMA as measured by TGA. The vertical capped lines through symbols indicate error from TGA measurements.

nanoparticles are $101.2 \pm 0.8 \mathrm{~nm}$ for bare (B) silica and $112.4 \pm 1.3 \mathrm{~nm}$ for flurinated (F and FF) silica. (ii) The fluorinated silica nanoparticles have an average surface coverage of $\sim 73 \%$ for $\mathrm{F}$ and $\sim 120 \%$ for FF indicating multilayer fluorination at the surface of these samples.

3.3. Silica Concentration in Polymer Nanocomposites. The silica concentration of the samples was determined by thermogravimetric analysis and the results are presented in Figure 4. The final silica concentrations were grouped into "low" and "high" concentrations containing $0.85-1.38 \%$ and $2.5-3.30 \%$ silica, respectively. Recalling that the surface tethering densities are represented with "B" for bare silica, " $\mathrm{F}$ " for low tethering density, and "FF" for high tethering density, each silica/PMMA is labeled with both of these markers, such as B-Low or B-High, in the following sections.

\subsection{Effect of Silica Surface Modification and Concentration} on Foam Morphology. Polymer nanocomposite samples were processed with supercritical $\mathrm{CO}_{2}$ and the resulting foam morphologies obtained via scanning electron microscopy (SEM) are presented in Figure 5. Visual observation of the SEM images clearly shows the difference between the foam morphologies of nanocomposites containing bare and fluorinated silica nanoparticles. At low and high concentrations of bare silica nanoparticles, the foam morphology (average cell size, cell density) looks similar to that of neat PMMA even though the nucleation mechanism between these two types of samples are completely different: homogeneous in neat PMMA versus heterogeneous in filled PMMA. The similarity of the foam morphologies is mainly attributed to the poor interaction of $\mathrm{CO}_{2}$ with bare silica and also to the formation of silica agglomerates inside the polymer matrix (micrograph not shown). On the other hand, all four samples containing fluorinated silica nanoparticles (F-Low, F-High, FF-Low, and FF-High) have remarkably low (average) cell sizes and high cell densities. In order to quantify these visual observations, the foamed samples' cell density and cell size distributions were characterized by image processing.

Cell density calculations were based on a method described by Kumar and Suh [51]. Typically, a micrograph showing more than 100 bubbles (cells) was chosen for the analysis. The number of bubbles $(n)$ was counted and the number of bubbles per unit volume $(N)$ was calculated using the following equation:

$$
N=\left(\frac{n M^{2}}{A}\right)^{3 / 2}
$$

where $M$ is the magnification factor and $A$ is the true area of the SEM image. According to this method, the cell density of the samples was calculated from five different images collected from the center and the edges of the fracture surface.

The cell density measurements confirmed that neat PMMA, and the polymer nanocomposite samples prepared with bare silica nanoparticles have very low cell densities compared to the foamed samples containing fluorinated silica nanoparticles regardless of the tethering density and silica concentration (Figure 6(a)). The neat PMMA foam has an average cell density of $7.5 \pm 0.5 \times 10^{8}$ cells $/ \mathrm{cm}^{3}$. The foamed samples containing bare silica nanoparticles formed agglomerates (micrograph not shown), which evidently affected the cell density. A remarkable difference is observed in cell densities between the samples containing bare and fluorinated silica containing PMMA. This is because surface chemistry affects both the dispersion and distribution of silica nanoparticles in the PMMA matrix and the interaction between silica nanoparticles and $\mathrm{CO}_{2}$ molecules. It is well known that supercritical $\mathrm{CO}_{2}$ exhibits high affinity for fluorocarbons, fluoroethers, siloxanes, and polycarbonates [52]. Fluorination of silica decreases the surface energy and leads to a decreased critical activation energy required for nucleation of $\mathrm{CO}_{2}$ bubbles [21]. On the other hand, among the fluorinated samples, the highest cell density was achieved for high concentration samples (FF) indicating that the silica concentration is the determining factor.

The immediate change in cell density upon surface modification (going from $\mathrm{B}$ to $\mathrm{F}$ ) is quite impressive showing almost a 100 -fold increase. This suggests that there is a tremendous effect of surface chemistry on foam morphology. On the other hand, increasing surface tethering density from $\sim 73 \%$ to over $100 \%$ did not change the cell density values significantly. It is, therefore, important to have the proper surface chemistry but having too much of $\mathrm{CO}_{2}$-philic chemical groups on the nanofiller surface does not further improve cell density values. This result can be explained by the selective placement of $\mathrm{CO}_{2}$ molecules at the filler/polymer interface. Even a modest selectivity achieved through surface modification leads to improved results. Unfortunately tethering densities lower than $\sim 70 \%$ were not available in the current study; therefore, it is not possible to state if there is 


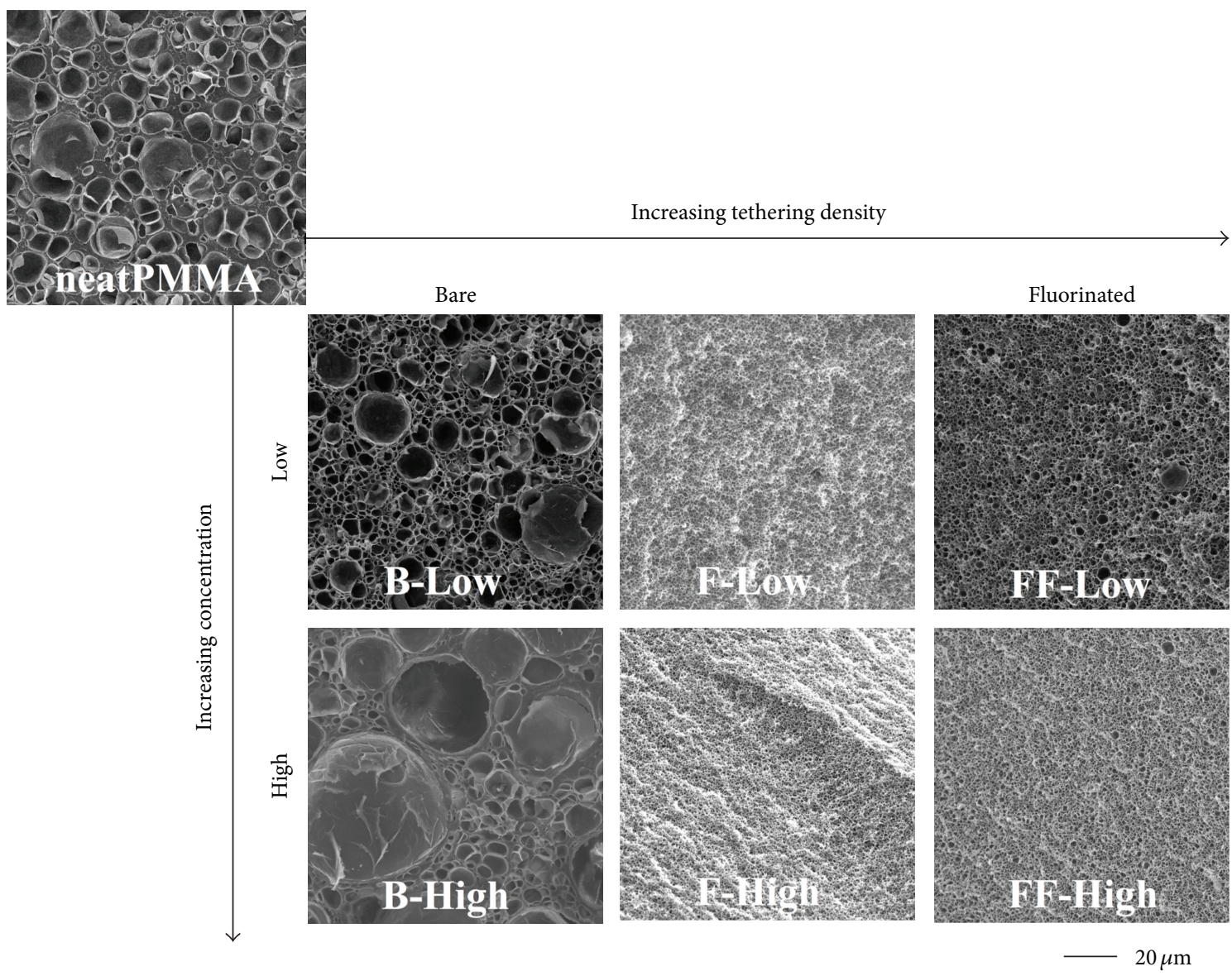

FIGURE 5: SEM images of the foamed samples with varying surface modification and concentration.

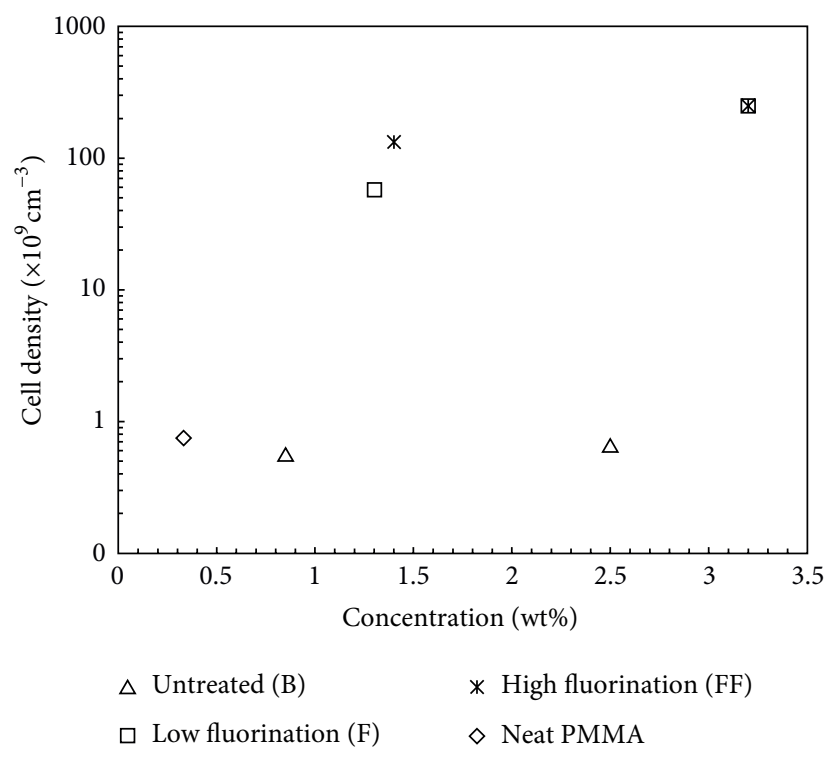

(a)

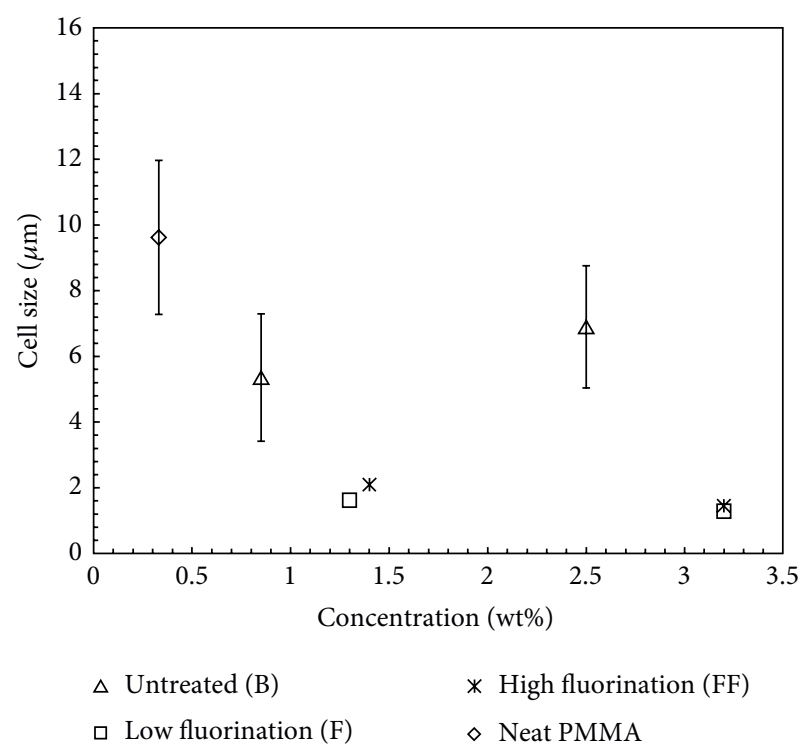

(b)

FIGURE 6: (a) Cell density and (b) average cell size of the neat PMMA, nanocomposites containing bare nanosilica (B), nanocomposites with surface treated silica at low fluorination (F) and high fluorination (FF). Error bars represent standard error of five samples and error bars smaller than symbol size are not shown. 
an optimum tethering density that would lead to the best results (high cell density, small average pore size).

The cell sizes of the samples were measured from SEM images. The results of the average cell diameters are presented in Figure 6(b). The average cell diameter of the neat PMMA polymer foam was calculated to be $9.62 \pm 5.22 \mu \mathrm{m}$. The cell size measurements of the samples containing bare silica nanoparticles showed that these samples have comparably lower average cell diameters. However, the high standard deviation in neat PMMA and nanocomposites containing bare silica nanoparticles indicate the presence of a wide distribution of cell sizes in these samples. This similarity in the cell size distribution between foamed PMMA and B samples is attributed to the fact that all of these samples had homogeneous nucleation. Bare silica containing samples additionally had heterogeneous nucleation; however this secondary mechanism must have been quite ineffective due to the similarities in the foam morphologies between PMMA and B samples. Previous studies reported that homogeneous nucleation leads to a wide cell size distribution whereas heterogeneous nucleation leads to a narrow cell size distribution [13]. Obviously, the bare silica containing samples' cell size distribution is similar to that of neat PMMA because both systems undergo homogeneous nucleation, but the average cell size in bare silica containing samples is relatively lower than that of neat PMMA because these samples also experience heterogeneous nucleation. Contrary to neat PMMA and bare silica containing PMMA (B samples), the surface fluorinated silica nanoparticle containing samples ( $\mathrm{F}$ and FF) have significantly lower average cell sizes and smaller standard deviations. The smallest average cell sizes were achieved at higher concentrations of silica ("high" samples). Surface tethering density had a minor effect on the results. These observations are in agreement with the results obtained for cell densities (Figure 6(a)).

\subsection{Effect of Processing Conditions on Foam Morphology.} During supercritical $\mathrm{CO}_{2}$ saturation, $\mathrm{CO}_{2}$ also serves as a plasticizer for PMMA [53-55] and it was shown that $\mathrm{CO}_{2}$ has greater solubility in polymers with branched structures compared to linear polymers. In the current study, carbon dioxide has comparably high solubility in PMMA due to specific interactions it has with the carbonyl groups of PMMA. The higher affinity between $\mathrm{CO}_{2}$ and carbonyl groups of PMMA implies higher plasticization capacity, which is manifested in lowered glass transition temperature and viscosity [56]. The solubility of $\mathrm{CO}_{2}$ in PMMA was reported to be about $6.3 \%$ (by weight) at $20^{\circ} \mathrm{C}$ and $6.89 \mathrm{MPa}, 9.3 \%$ at $40^{\circ} \mathrm{C}$ and $13.78 \mathrm{MPa}$, and $10.5 \%$ at $70^{\circ} \mathrm{C}$ and $20.67 \mathrm{MPa}$ [57]. Therefore, because the solubility of $\mathrm{CO}_{2}$ in PMMA changes as a function of processing parameters (pressure and temperature), it is necessary to also consider the effect of the processing parameters on the final foam morphology.

In a typical experiment, the polymer nanocomposite sample was saturated with supercritical $\mathrm{CO}_{2}$ at a preselected temperature and pressure. In order to understand the effect of processing conditions on foam morphology, several experiments were conducted at 65 and $85^{\circ} \mathrm{C}$ and at $8.97,13.45$, and $17.93 \mathrm{MPa}$. For this study only one sample containing highly fluorinated silica nanoparticles at high concentration (FFHigh with $2.9 \%$ silica content) was used, thereby, eliminating sample variations and the effect of surface modification and silica concentration. Other processing parameters such as saturation time, rate of pressure reduction, bubble fixation temperature, and foaming duration were all kept constant at $24 \mathrm{hrs}, 1.5 \mathrm{MPa} / \mathrm{s}, 62^{\circ} \mathrm{C}$, and $1 \mathrm{~min}$, respectively. The resulting SEM micrographs of fracture surfaces are presented in Figure 7. Visual observation of the SEM micrographs indicates uniform cell size distribution across samples.

The effect of pressure on cell density and cell size at two different temperatures is presented in Figure 8. A slight decrease in cell density and a slight increase in average cell size are observed in Figures 8(a) and 8(b), although the changes are within experimental error. These results suggest that the effect of soaking pressure is low compared to the effect of surface modification for the samples investigated (FF-High with $2.9 \%$ silica content). This result can be explained by the fact that these samples already present high affinity towards $\mathrm{CO}_{2}$ due to the presence of fluorinated surfactants, and therefore, nucleation of supercritical $\mathrm{CO}_{2}$ at the (surface modified) silica/PMMA interface is already optimized.

The effect of temperature was found to be more complex than the effect of pressure. The effect of temperature at 8.97 $\mathrm{MPa}$ is presented in Figure 9. Results suggest a change of mechanism as a function of temperature. For example, at the lowest temperature, the cell density is low. Increasing the temperature leads to an increased cell density initially, but further increase in temperature leads to decreasing cell densities. These results can be explained by the change in the glass transition temperature of PMMA upon supercritical $\mathrm{CO}_{2}$ saturation. It was shown before that $\mathrm{CO}_{2}$ acts as a plasticizer for PMMA [55] and increasing pressure and temperature lead to more carbon dioxide absorption. The original glass transition temperature of neat PMMA is around $105^{\circ} \mathrm{C}$. Previous studies reported that the plasticizer effect of carbon dioxide becomes evident at $8 \mathrm{MPa}$ at which the glass transition temperature is reported to be $40^{\circ} \mathrm{C}[53,58]$. It was also shown that as the amount of absorbed $\mathrm{CO}_{2}$ increases, the glass transition temperature decreases. When foaming takes place at temperatures lower than the glass transition temperature, not all nucleated bubbles can grow due to the high viscosity (resistance) of the PMMA bulk. This leads to low cell density at low temperatures. At high temperatures (above the $T_{g}$ ), although bubble growth is easier due to low polymer viscosity, growing bubbles could easily coalesce leading to decreased cell density. The highest cell density could be observed in the vicinity of the glass transition temperature as the viscosity at this state would be considerably higher than that at high temperatures preventing bubble coalescence but low enough that bubbles can grow.

Table 2 summarizes all the samples tested. The first row represents the neat PMMA sample, taken as a control. The next six samples indicate the effect of concentration and surface modification on cell density and cell size. The operating conditions (temperature and pressure) of the foaming process were varied for a single sample containing highly fluorinated silica nanoparticles (FF) with high concentration (2.9\%). This 

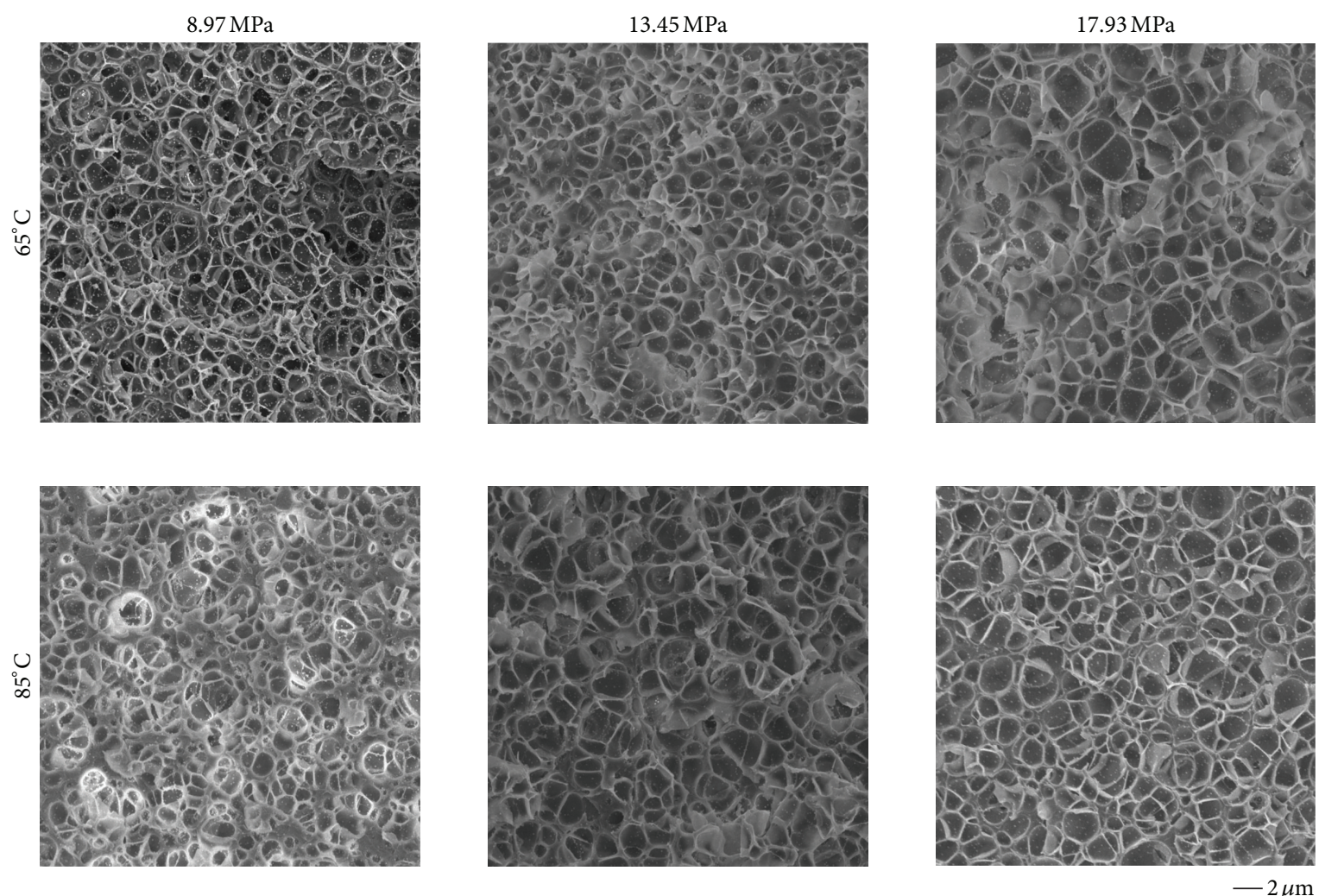

FIGURE 7: SEM images of the foamed highly fluorinated, high concentration (FF-High) sample at various pressures and temperatures.

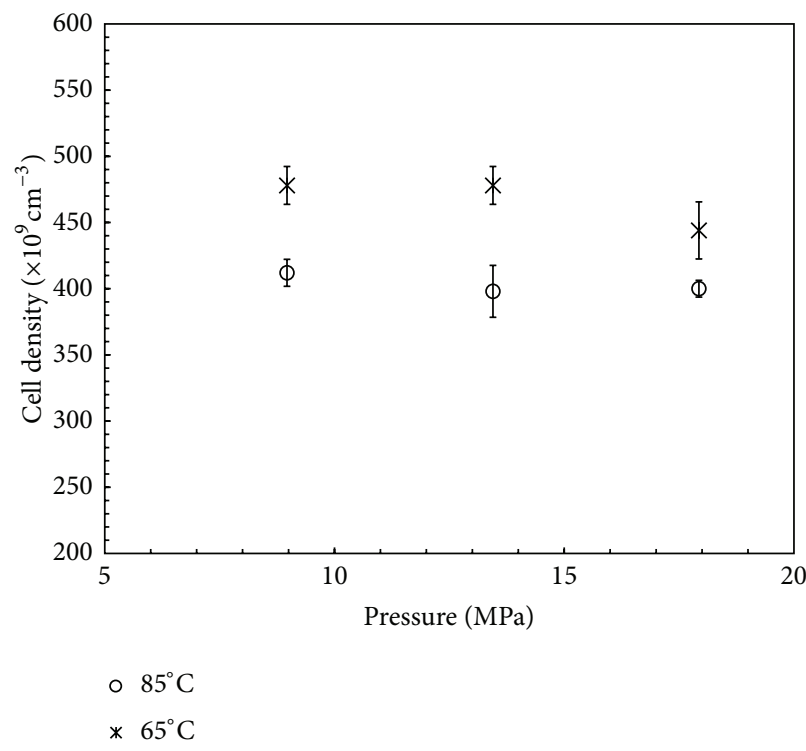

(a)

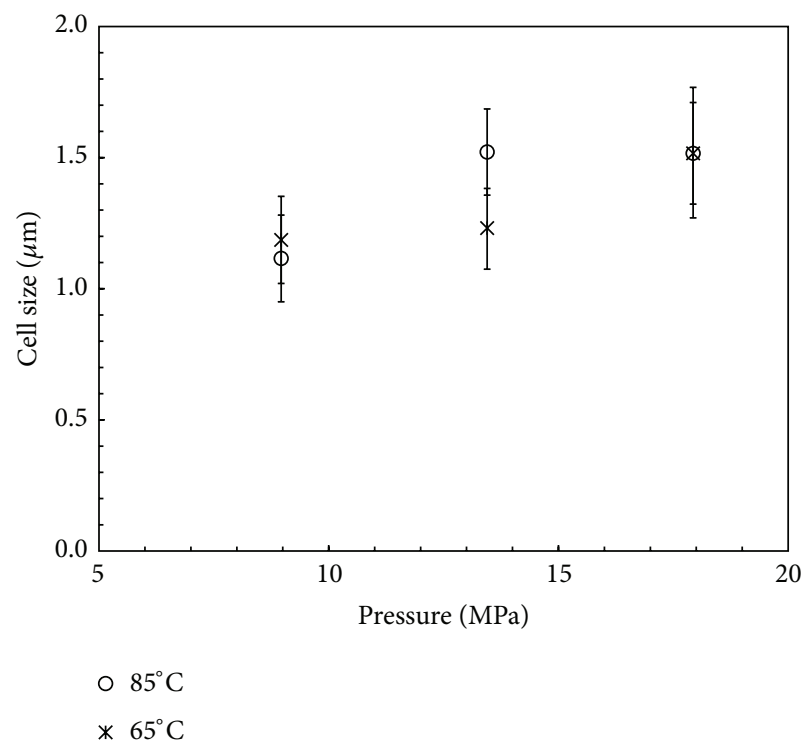

(b)

FIGURE 8: (a) Cell density and (b) cell size of the highly fluorinated, high concentration (FF-High) sample processed at 65 and $85^{\circ} \mathrm{C}$ at saturation pressures 8.97, 13.45 and $17.93 \mathrm{MPa}$. The error bars show the standard error of five samples. 
TABLE 2: Summary of the cell density and cell size measurements for all samples used in the current study. $T$ is the foaming temperature and $P$ is the saturation pressure.

\begin{tabular}{lcccccc}
\hline Sample label & $\begin{array}{c}\text { Surface modification } \\
(\%)\end{array}$ & $\begin{array}{c}\text { Concentration } \\
(\mathrm{wt} \%)\end{array}$ & $T\left({ }^{\circ} \mathrm{C}\right)$ & $P(\mathrm{MPa})$ & $\begin{array}{c}\text { Cell Density } \\
\left(10^{9} \mathrm{~cm}^{-3}\right)\end{array}$ & $\begin{array}{c}\text { Cell Diameter }^{\dagger} \\
(\mu \mathrm{m})\end{array}$ \\
\hline PMMA & - & - & 40 & 8.97 & $0.75 \pm 0.05$ & $9.62 \pm 5.22$ \\
\hline B & - & 0.85 & 40 & 8.97 & $0.57 \pm 0.09$ & $5.36 \pm 4.33$ \\
B & - & 2.50 & 40 & 8.97 & $0.67 \pm 0.29$ & $6.90 \pm 4.14$ \\
\hline F & $\sim 73$ & 1.29 & 40 & 8.97 & $57.1 \pm 10.4$ & $1.62 \pm 0.40$ \\
F & $\sim 73$ & 3.16 & 40 & 8.97 & $248 \pm 12$ & $1.29 \pm 0.29$ \\
\hline FF & $>100$ & 1.38 & 40 & 8.97 & $132 \pm 16$ & $2.10 \pm 0.80$ \\
FF & $>100$ & 3.20 & 40 & 8.97 & $248 \pm 23$ & $1.45 \pm 0.54$ \\
FF* & $>100$ & 2.9 & 40 & 8.97 & $380 \pm 91$ & $1.38 \pm 0.44$ \\
FF $^{*}$ & $>100$ & 2.9 & 65 & 8.97 & $478 \pm 32$ & $1.19 \pm 0.37$ \\
FF $^{*}$ & $>100$ & 2.9 & 65 & 13.45 & $478 \pm 43$ \\
FF $^{*}$ & $>100$ & 2.9 & 65 & 17.93 & $444 \pm 48$ & $1.23 \pm 0.34$ \\
FF $^{*}$ & $>100$ & 2.9 & 75 & 8.97 & $464 \pm 30$ & $1.52 \pm 0.56$ \\
FF $^{*}$ & $>100$ & 2.9 & 85 & 8.97 & $412 \pm 23$ \\
FF $^{*}$ & $>100$ & 2.9 & 85 & 13.45 & $398 \pm 44$ \\
FF $^{*}$ & $>100$ & 2.9 & 85 & 17.93 & $400 \pm 14$ & $1.06 \pm 0.32$ \\
\hline
\end{tabular}

* These samples were all processed from the same silica synthesis batch.

${ }^{\dagger}$ Standard deviation is given.

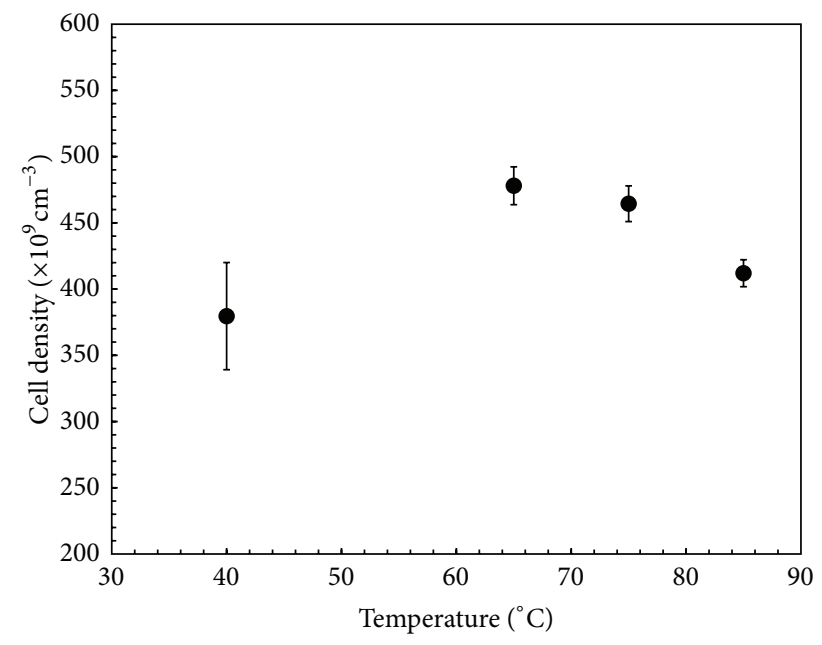

FIgURE 9: Cell densities of FF-High samples processed at 8.97 MPa as a function of saturation temperature. Error bars are the standard error for five samples.

strategy not only eliminates the concentration and surface modification effect but also ensures heterogeneous bubble nucleation mechanism is the dominant mechanism.

The cell densities and average cell sizes obtained in the current study are compared to those obtained from other studies performed with PMMA in Figure 10. Although the processing conditions in various studies differ from each other, considering that the goal of all of these studies is to obtain the greatest cell densities and the smallest average cell sizes, comparison of various results might prove to be useful. However, in order to achieve a direct comparison, results from various studies were normalized by the results of the

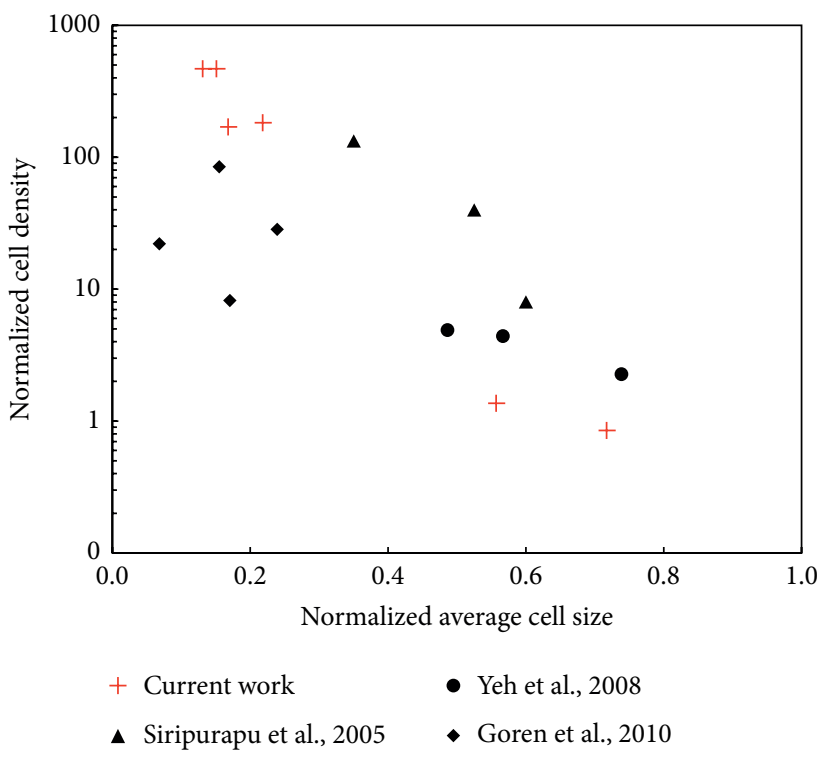

FIGURE 10: Comparison of normalized cell densities and normalized average cell sizes of various silica/PMMA nanocomposite foams.

neat PMMA in each study. In general, it is well known that cell density and cell size are inversely correlated with each other. This phenomenon can easily be observed in Figure 10.

\section{Conclusions}

Silica/poly(methyl methacrylate), PMMA, nanocomposites containing bare and fluoroalkane modified silica nanoparticles with an average size of $100 \mathrm{~nm}$ were studied under 
varying supercritical carbon dioxide conditions. The effect of silica nanoparticle concentration and the extent of fluorination was studied systematically. The fracture surfaces of foamed samples were imaged with field emission scanning electron microscope and image processing tools were utilized to obtain cell density and average cell size. Our findings led to the following conclusions.

Surface modification of silica nanoparticles with $\mathrm{CO}_{2}$ philic fluoroalkane molecules significantly improved foam morphology. The average cell size decreased from $9.62 \mu \mathrm{m}$ in neat PMMA to $1.06 \mu \mathrm{m}$ with the addition of $2.9 \%$ highly surface modified silica nanoparticles at $75^{\circ} \mathrm{C}$ and $8.97 \mathrm{MPa}$. The effect of surface fluorination of silica nanoparticles on cell size was observed for all nanocomposite samples regardless of the nanofiller concentration. Even the low fluorinated samples showed 6-7 times decrease in average cell size.

However, the extent of surface coverage (tethering density) of silica nanoparticles had a minor effect on foam morphology. The average cell sizes increased approximately $20 \%$ upon going from $\sim 73 \%$ surface coverage to over $100 \%$ surface coverage.

Increasing silica concentration had a remarkable effect on the average cell size and cell density. Increasing silica concentration from $\sim 1.3 \%$ to $\sim 3.2 \%$ led to a $\sim 35 \%$ decrease in average cell size.

Foam morphology strongly depends on the foaming temperature in reference to the glass transition temperature of the polymer. Although the glass transition of the neat PMMA used in the current study is around $105^{\circ} \mathrm{C}$, soaking with supercritical $\mathrm{CO}_{2}$, which acts as a plasticizer, decreased it to approximately $65^{\circ} \mathrm{C}$ at $8.97 \mathrm{MPa}$ soaking pressure. As a result, the foam morphology below and above the new glass transition temperature was influenced by different viscoelastic properties of the PMMA matrix. Our results suggest that the maximum cell density is reached in the vicinity of the glass transition temperature because the bubble growth was impeded either by high viscosity below the $T_{g}$ or by bubble coalescence above the $T_{g}$.

\section{Acknowledgments}

Deniz Rende is supported by a fellowship from the Scientific and Technological Research Council of Turkey (TUBITAK), 2219 Program. This material is based upon work supported by the National Science Foundation under Grant nos. 0117792, 0500324, and 1003574.

\section{References}

[1] M. A. Shafi, K. Joshi, and R. W. Flumerfelt, "Bubble size distributions in freely expanded polymer foams," Chemical Engineering Science, vol. 52, no. 4, pp. 635-644, 1997.

[2] S. L. Everitt, O. G. Harlen, and H. J. Wilson, "Competition and interaction of polydisperse bubbles in polymer foams," Journal of Non-Newtonian Fluid Mechanics, vol. 137, no. 1-3, pp. 60-71, 2006.

[3] D. Klempner, V. Sendijarevic, and R. Aseeva, Handbook of Polymeric Foams and Foam Technology, Hanser Gardner Publications, Kempten, Germany, 2004.
[4] L. J. Lee, C. Zeng, X. Cao, X. Han, J. Shen, and G. Xu, "Polymer nanocomposite foams," Composites Science and Technology, vol. 65, no. 15-16, pp. 2344-2363, 2005.

[5] G. A. Banyay, M. M. Shaltout, H. Tiwari, and B. V. Mehta, "Polymer and composite foam for hydrogen storage application," Journal of Materials Processing Technology, vol. 191, no. 1-3, pp. 102-105, 2007.

[6] Z. Liu, G. Bai, Y. Huang et al., "Reflection and absorption contributions to the electromagnetic interference shielding of single-walled carbon nanotube/polyurethane composites," Carbon, vol. 45, no. 4, pp. 821-827, 2007.

[7] Y. Wang, G. A. Sotzing, and R. A. Weiss, "Conductive polymer foams as sensors for volatile amines," Chemistry of Materials, vol. 15, no. 2, pp. 375-377, 2003.

[8] D. X. Yan, K. Dai, Z. D. Xiang, Z. M. Li, X. Ji, and W. Q. Zhang, "Electrical conductivity and major mechanical and thermal properties of carbon nanotube-filled polyurethane foams," Journal of Applied Polymer Science, vol. 120, no. 5, pp. 3014-3019, 2011.

[9] F. C. Chiu, S. M. Lai, C. M. Wong, and C. H. Chang, "Properties of calcium carbonate filled and unfilled polystyrene foams prepared using supercritical carbon dioxide," Journal of Applied Polymer Science, vol. 102, no. 3, pp. 2276-2284, 2006.

[10] T. Mori, H. Hayashi, M. Okamoto, S. Yamasaki, and H. Hayami, "Foam processing of polyethylene ionomers with supercritical $\mathrm{CO}_{2}$," Composites A, vol. 40, no. 11, pp. 1708-1716, 2009.

[11] M. Antunes, V. Realinho, A. B. Martínez, E. Solórzano, M. A. Rodríguez-Pérez, and J. I. Velasco, "Heat transfer of mineralfilled polypropylene foams," Defect and Diffusion Forum, vol. 297-301, pp. 990-995, 2010.

[12] Q. Wu, N. Zhou, and D. Zhan, "Effect of processing parameters and vibrating field on poly(Vinyl chloride) microcellular foam morphology," Polymer, vol. 48, no. 8, pp. 851-859, 2009.

[13] W. Zhai, J. Yu, L. Wu, W. Ma, and J. He, "Heterogeneous nucleation uniformizing cell size distribution in microcellular nanocomposites foams," Polymer, vol. 47, no. 21, pp. 7580-7589, 2006.

[14] L. Chen, B. Goren, R. Ozisik, and L. Schadler, "Controlling bubble density in MWNT/polymer nanocomposite foams by MWNT surface modification," Composites in Science and Technology, vol. 72, pp. 190-196, 2012.

[15] D. Eaves, Handbook of Polymer Foams, Smithers Rapra Press, Shawbury, UK, 2004.

[16] Y. W. Chang, D. Lee, and S. Y. Bae, "Preparation of polyethyleneoctene elastromer/clay nanocomposite and microcellular foam processed in supercritical carbon dioxide," Polymer International, vol. 55, no. 2, pp. 184-189, 2006.

[17] D. Wee, D. G. Seong, and J. R. Youn, "Processing of microcellular nanocomposite foams by using a supercritical fluid," Fibers and Polymers, vol. 5, no. 2, pp. 160-169, 2004.

[18] N. S. Ramesh, D. H. Rasmussen, and G. A. Campbell, "Heterogeneous nucleation of microcellular foams assisted by the survival of microvoids in polymers containing low glass transition particles. Part I: mathematical modeling and numerical simulation," Polymer Engineering and Science, vol. 34, no. 22, pp. 1685-1697, 1994.

[19] Y. P. Handa and Z. Zhang, "Novel stress-induced nucleation and foaming process and its applications in making homogeneous foams, anisotropic foams, and multilayered foams," Cellular Polymers, vol. 19, no. 2, pp. 77-91, 2000. 
[20] S. N. Leung, A. Wong, L. C. Wang, and C. B. Park, "Mechanism of extensional stress-induced cell formation in polymeric foaming processes with the presence of nucleating agents," The Journal of Supercritical Fluids, vol. 63, pp. 187-198, 2012.

[21] K. Goren, L. Chen, L. S. Schadler, and R. Ozisik, "Influence of nanoparticle surface chemistry and size on supercritical carbon dioxide processed nanocomposite foam morphology," Journal of Supercritical Fluids, vol. 51, no. 3, pp. 420-427, 2010.

[22] L. Chen, R. Ozisik, and L. S. Schadler, "The influence of carbon nanotube aspect ratio on the foam morphology of MWNT/PMMA nanocomposite foams," Polymer, vol. 51, no. 11, pp. 2368-2375, 2010.

[23] L. Chen, L. S. Schadler, and R. Ozisik, "An experimental and theoretical investigation of the compressive properties of multi-walled carbon nanotube/poly(methyl methacrylate) nanocomposite foams," Polymer, vol. 52, no. 13, pp. 2899-2909, 2011.

[24] Y. H. Kim, S. J. Choi, J. M. Kim, M. S. Han, W. N. Kim, and K. T. Bang, "Effects of organoclay on the thermal insulating properties of rigid polyurethane foams blown by environmentally friendly blowing agents," Macromolecular Research, vol. 15, no. 7, pp. 676-681, 2007.

[25] C. Jo and H. E. Naguib, "Effect of nanoclay and foaming conditions on the mechanical properties of HDPE-clay nanocomposite foams," Journal of Cellular Plastics, vol. 43, no. 2, pp. 111-121, 2007.

[26] S. M. Seraji, M. K. Razavi Aghjeh, M. Davari, M. Salami Hosseini, and S. Khelgati, "Effect of clay dispersion on the cell structure of LDPE/clay nanocomposite foams," Polymer Composites, vol. 32, no. 7, pp. 1095-1105, 2011.

[27] C. Zeng, X. Han, L. J. Lee, K. W. Koelling, and D. L. Tomasko, "Polymer-clay nanocomposite foams prepared using carbon dioxide," Advanced Materials, vol. 15, no. 20, pp. 1743-1747, 2003.

[28] P. H. Nam, P. Maiti, M. Okamoto et al., "Foam processing and cellular structure of polypropylene/clay nanocomposites," Polymer Engineering and Science, vol. 42, no. 9, pp. 1907-1918, 2002.

[29] W. G. Zheng, Y. H. Lee, and C. B. Park, "Use of nanoparticles for improving the foaming behaviors of linear PP," Journal of Applied Polymer Science, vol. 117, no. 5, pp. 2972-2979, 2010.

[30] M. C. Saha, M. E. Kabir, and S. Jeelani, "Enhancement in thermal and mechanical properties of polyurethane foam infused with nanoparticles," Materials Science and Engineering A, vol. 479, no. 1-2, pp. 213-222, 2008.

[31] S. H. Lee, M. Kontopoulou, and C. B. Park, "Effect of nanosilica on the co-continuous morphology of polypropylene/polyolefin elastomer blends," Polymer, vol. 51, no. 5, pp. 1147-1155, 2010.

[32] W. Zhai, C. B. Park, and M. Kontopoulou, "Nanosilica addition dramatically improves the cell morphology and expansion ratio of polypropylene heterophasic copolymer foams blown in continuous extrusion," Industrial and Engineering Chemistry Research, vol. 50, no. 12, pp. 7282-7289, 2011.

[33] S. Siripurapu, J. M. DeSimone, S. A. Khan, and R. J. Spontak, "Controlled foaming of polymer films through restricted surface diffusion and the addition of nanosilica particles or $\mathrm{CO}_{2}$ philic surfactants," Macromolecules, vol. 38, no. 6, pp. 22712280, 2005.

[34] J. M. Yeh, K. C. Chang, C. W. Peng et al., "Effect of vinylmodified silica and raw silica particles on the properties of as-prepared polymer-silica nanocomposite foams," Journal of Nanoscience and Nanotechnology, vol. 8, no. 12, pp. 6297-6305, 2008.
[35] M. Sauceau, C. Nikitine, E. Rodier, and J. Fages, "Effect of supercritical carbon dioxide on polystyrene extrusion," Journal of Supercritical Fluids, vol. 43, no. 2, pp. 367-373, 2007.

[36] J. I. Velasco, M. Antunes, V. Realinho, and M. Ardanuy, "Characterization of rigid polypropylene-based microcellular foams produced by batch foaming processes," Polymer Engineering \& Science, vol. 51, pp. 2120-2128, 2011.

[37] M. A. Treece and J. P. Oberhauser, "Processing of polypropylene-clay nanocomposites: single-screw extrusion with in-line supercritical carbon dioxide feed versus twin-screw extrusion," Journal of Applied Polymer Science, vol. 103, no. 2, pp. 884-892, 2007.

[38] L. Urbanczyk, M. Alexandre, C. Detrembleur, C. Jérôme, and C. Calberg, "Extrusion foaming of poly(styrene-coacrylonitrile)/clay nanocomposites using supercritical $\mathrm{CO}_{2}$," Macromolecular Materials and Engineering, vol. 295, no. 10, pp. 915-922, 2010.

[39] M. Sauceau, J. Fages, A. Common, C. Nikitine, and E. Rodier, "New challenges in polymer foaming: a review of extrusion processes assisted by supercritical carbon dioxide," Progress in Polymer Science, vol. 36, no. 6, pp. 749-766, 2011.

[40] S. P. Nalawade, F. Picchioni, and L. P. B. M. Janssen, "Supercritical carbon dioxide as a green solvent for processing polymer melts: processing aspects and applications," Progress in Polymer Science, vol. 31, no. 1, pp. 19-43, 2006.

[41] X. Dai, Z. Liu, Y. Wang, G. Yang, J. Xu, and B. Han, “High damping property of microcellular polymer prepared by friendly environmental approach," Journal of Supercritical Fluids, vol. 33, no. 3, pp. 259-267, 2005.

[42] L. Chen, D. Rende, L. S. Schadler, and R. Ozisik, "Polymer nanocomposite foams," Journal of Materials Chemistry A, vol. 1, pp. 3837-3850, 2013.

[43] J. Shen, C. Zeng, and L. J. Lee, "Synthesis of polystyrene-carbon nanofibers nanocomposite foams," Polymer, vol. 46, no. 14, pp. 5218-5224, 2005.

[44] N. Athanasopoulos, A. Baltopoulos, M. Matzakou, A. Vavouliotis, and V. Kostopoulos, "Electrical conductivity of polyurethane/MWCNT nanocomposite foams," Polymer Composites, vol. 33, pp. 1302-1312, 2012.

[45] S. Gross, D. Camozzo, V. Di Noto, L. Armelao, and E. Tondello, "PMMA: a key macromolecular component for dielectric low$\kappa$ hybrid inorganic-organic polymer films," European Polymer Journal, vol. 43, no. 3, pp. 673-696, 2007.

[46] W. Stöber, A. Fink, and E. Bohn, "Controlled growth of monodisperse silica spheres in the micron size range," Journal of Colloid And Interface Science, vol. 26, no. 1, pp. 62-69, 1968.

[47] M. Abramoff, P. Magelhaes, and S. Ram, "Image processing with imageJ," Biophotonics International, vol. 11, pp. 36-42, 2004.

[48] A. Kohno, N. Sakai, S. Matsui, and M. Nakagawa, "Enhanced durability of antisticking layers by recoating a silica surface with fluorinated alkylsilane derivatives by chemical vapor surface modification," Japanese Journal of Applied Physics, vol. 49, no. 6, Article ID 06GL12, 2010.

[49] K. Parker, R. T. Schneider, R. W. Siegel et al., "Molecular probe technique for determining local thermal transitions: the glass transition at Silica/PMMA nanocomposite interfaces," Polymer, vol. 51, no. 21, pp. 4891-4898, 2010.

[50] L. T. Zhuravlev, "Surface characterization of amorphous silica-a review of work from the former USSR," Colloids and Surfaces A, vol. 74, no. 1, pp. 71-90, 1993. 
[51] V. Kumar and N. Suh, "A process for making microcellular thermoplastic parts," Polymer Engineering \& Science, vol. 30, pp. 1323-1329, 1990.

[52] T. Sarbu, T. Styranec, and E. J. Beckman, "Non-fluorous polymers with very high solubility in supercritical $\mathrm{CO}_{2}$ down to low pressures," Nature, vol. 405, no. 6783, pp. 165-168, 2000.

[53] P. Alessi, A. Cortesi, I. Kikic, and F. Vecchione, "Plasticization of polymers with supercritical carbon dioxide: experimental determination of glass-transition temperatures," Journal of Applied Polymer Science, vol. 88, no. 9, pp. 2189-2193, 2003.

[54] I. Kikic, F. Vecchione, P. Alessi, A. Cortesi, F. Eva, and N. Elvassore, "Polymer plasticization using supercritical carbon dioxide: experiment and modeling," Industrial and Engineering Chemistry Research, vol. 42, no. 13, pp. 3022-3029, 2003.

[55] V. Di Noto, K. Vezzù, G. A. Giffin, F. Conti, and A. Bertucco, "Effect of high pressure $\mathrm{CO}_{2}$ on the structure of PMMA: a FT-IR study," The Journal of Physical Chemistry B, vol. 115, pp. 13519$13525,2011$.

[56] S. Lee and N. Ramesh, Polymeric Foams: Mechanisms and Materials, CRC Press, 2004.

[57] D. L. Tomasko, H. Li, D. Liu et al., "A review of $\mathrm{CO}_{2}$ applications in the processing of polymers," Industrial and Engineering Chemistry Research, vol. 42, no. 25, pp. 6431-6456, 2003.

[58] A. Kasturirangan, C. A. Koh, and A. S. Teja, "Glass-transition temperatures in $\mathrm{CO}_{2}$ + polymer systems: modeling and experiment," Industrial and Engineering Chemistry Research, vol. 50, no. 1, pp. 158-162, 2011. 

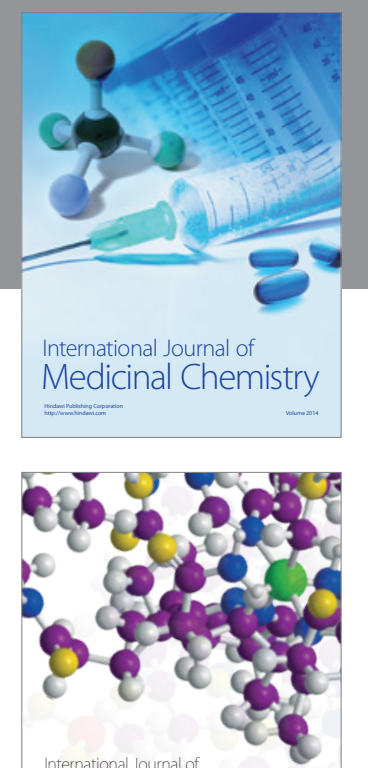

\section{Carbohydrate} Chemistry

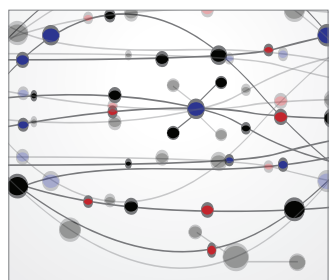

The Scientific World Journal
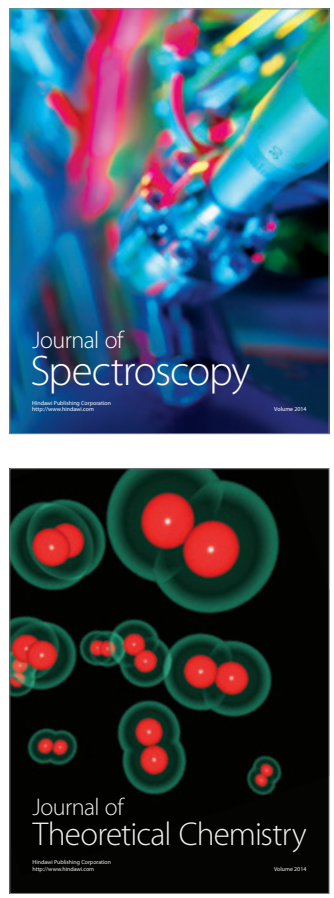
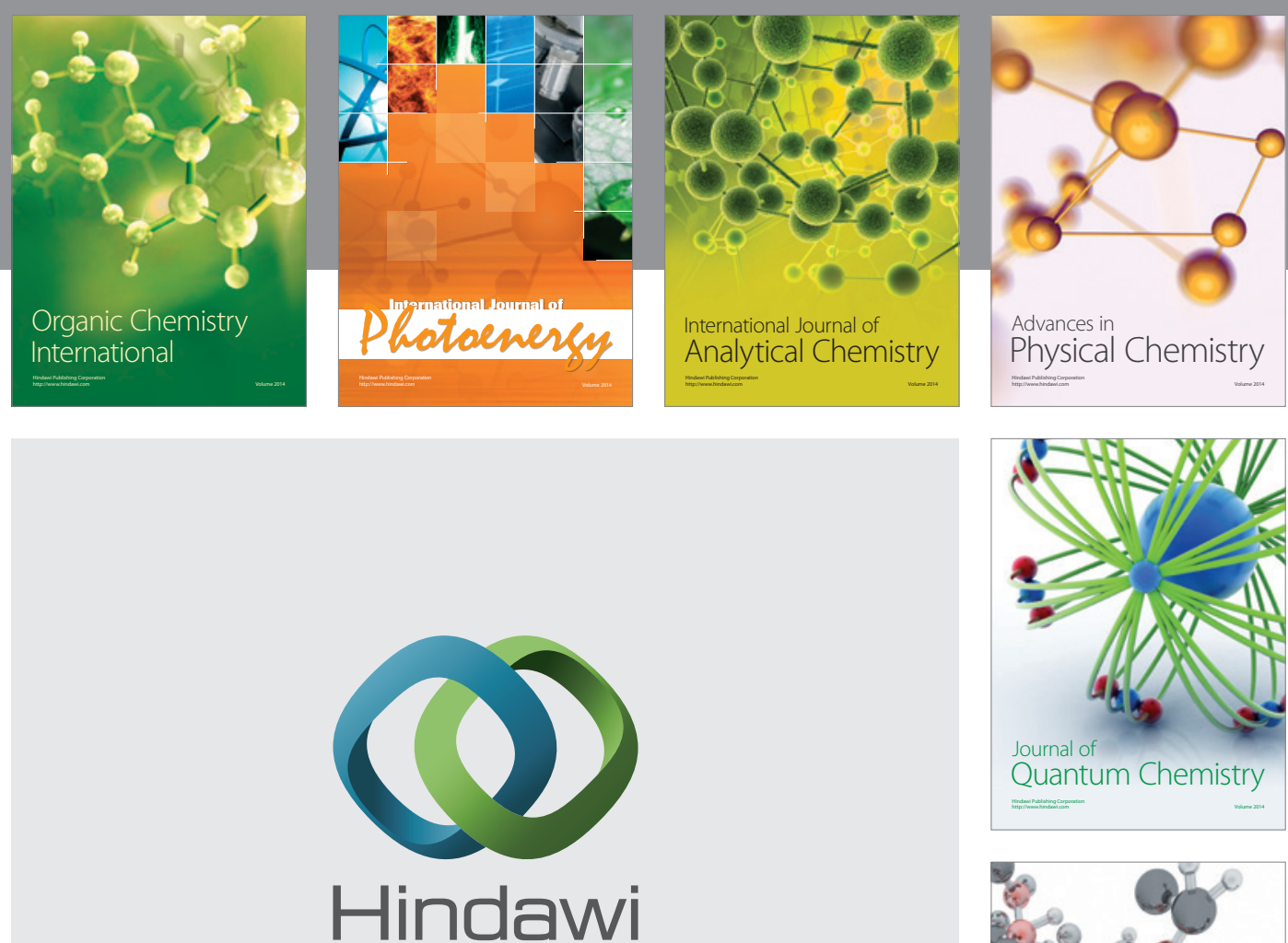

Submit your manuscripts at

http://www.hindawi.com

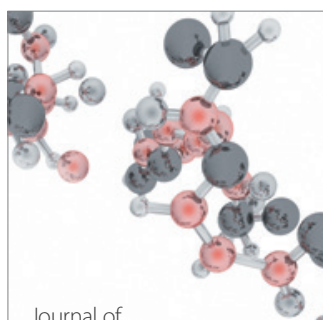

Analytical Methods

in Chemistry

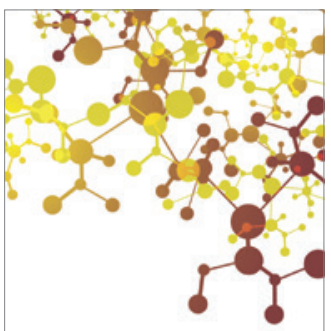

Journal of

Applied Chemistry

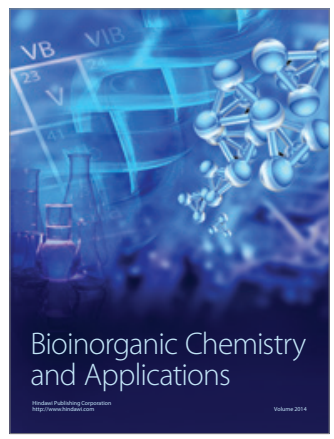

Inorganic Chemistry
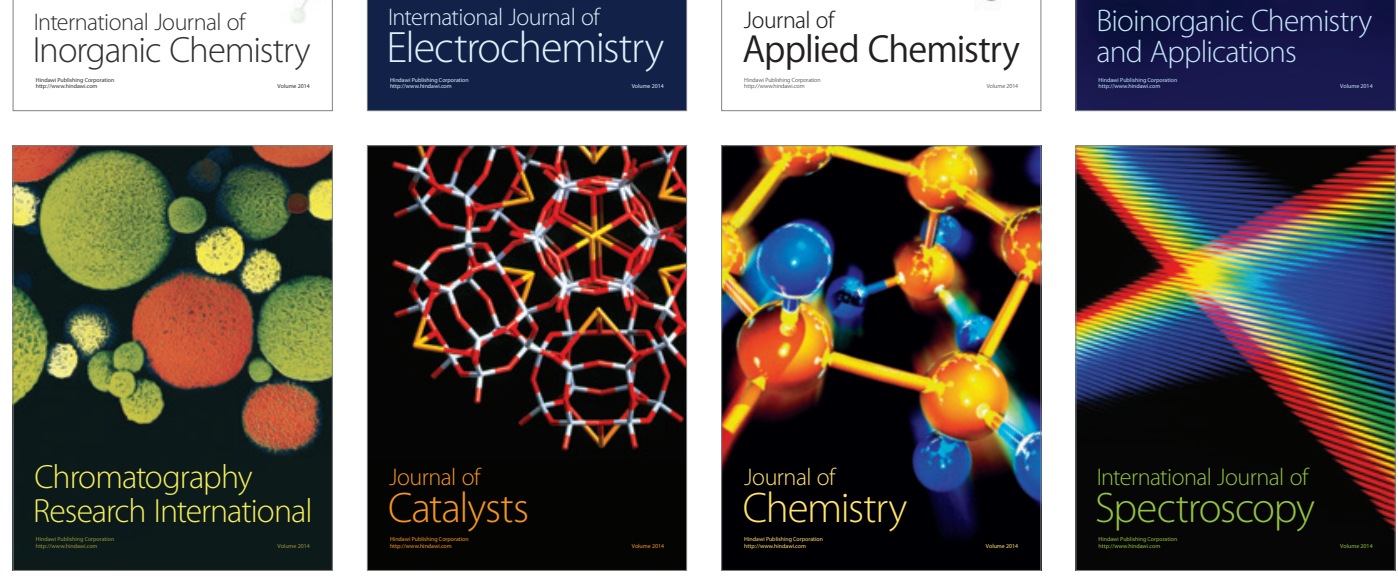